\title{
Severe and Prolonged Myelosuppression during Concomitant Temozolomide and Radiotherapy Treatment in a Patient with Glioblastoma Multiforme
}

\author{
Claudia Scaringi ${ }^{1 *}$, Vitaliana De Sanctis ${ }^{1}$, Giuseppe Minniti ${ }^{1}$, Raffaele Porrini ${ }^{2}$, \\ Alessia Carnevale ${ }^{1}$, Maurizio Valeriani ${ }^{1}$, Maria Christina Cox ${ }^{2}$, \\ Maria Antonietta Aloe Spiriti ${ }^{2}$, Giovanna Gentile ${ }^{3}$, Maurizio Simmaco ${ }^{3}$, \\ Luigi Ruco ${ }^{4}$, Agostino Tafuri ${ }^{2}$ and Riccardo Maurizi Enrici ${ }^{1}$ \\ ${ }^{1}$ Department of Radiation Oncology, S Andrea Hospital, University "Sapienza", Rome, Italy. \\ ${ }^{2}$ Department of Haematology, S Andrea Hospital, University "Sapienza", Rome, Italy. \\ ${ }^{3}$ NESMOS Department, Advanced Molecular Diagnostic Unit, S. Andrea Hospital, University \\ "Sapienza", Rome, Italy. \\ ${ }^{4}$ Department of Clinical and Molecular Medicine, S. Andrea Hospital, University "Sapienza”, Rome,
}

Italy.

Authors' contributions

This work was carried out in collaboration between all authors. All authors read and approved the final manuscript.

Article Information

DOI: $10.9734 /$ IJMPCR/2015/13957

Editor(s):

(1) Rakesh Kumar Tiwari, Chapman University School of Pharmacy, Chapman University Harry and Diane Rinker Health

Sciences Campus, Irvine, CA, USA.

Reviewers:

(1) Anonymous, Sungkyunkwan University School of Medicine, South Korea.

(2) Anonymous, Stanford University, USA.

(3) Anonymous, Fluminense Federal University, RJ, Brazil. (4) Kopecky Jindrich, Department of Clinical Oncology and Radiotherapy, Charles University Hospital and Faculty of Medicine in Hradec Kralove, Hradec Kralove, Czech Republic.

Complete Peer review History: http://www.sciencedomain.org/review-history.php?iid=785\&id=38\&aid=6767

Case Study

Received $11^{\text {th }}$ September 2014

Accepted $15^{\text {th }}$ October 2014

Published $5^{\text {th }}$ November 2014

\section{ABSTRACT}

Aims: We describe the case of a patient with glioblastoma (GBM) who developed severe and prolonged myelosuppression during concomitant daily temozolomide (TMZ) and radiotherapy (RT) 
treatment. Analysis of polymorphisms in genes correlated with TMZ-induced myelotoxicity was also performed.

Presentation of the Case: A 67-year-old man with diagnosis of GBM undergoing concomitant RTTMZ treatment developed severe and prolonged pancytopenia that led to discontinuation of TMZ and required frequent platelet and red cells transfusions. Analysis of single nucleotide polymorphisms (SNPs) in the genes $\mathrm{NAD}(\mathrm{P}) \mathrm{H}$ dehydrogenase, quinone 1 (NQO1) and glutathione S-transferase pi 1 (GSTP1) was carried out. Both SNPs were found to be wild-type.

Discussion: TMZ is an oral alkylating agent used for the treatment of glioblastoma. TMZ is usually considered well tolerated and safe, with nausea and mild myelosuppression being the most common side effects. However, severe haematologic adverse events have been also reported. Recently, there has been growing interest in gene polymorphisms that might be associated with an increased risk of hematologic toxicity.

Conclusion: Myelosuppression is a side effect that can occur relatively early during concomitant TMZ treatment and can negatively impact on patient's quality of life. Further studies are warranted to find out a correlation between genetic factors and the occurrence of severe hematologic toxicity.

Keywords: Temozolomide; glioblastoma; myelosuppression.

\section{ABBREVIATIONS}

GBM: Glioblastoma multiforme, TMZ: Temozolomide, RT: radiotherapy.

\section{INTRODUCTION}

Glioblastoma multiforme (GBM) is the most common malignant primary brain tumor in adults. The standard treatment for newly diagnosed glioblastoma consists of maximum safe surgical resection followed by radiotherapy (RT) with concomitant and adjuvant chemotherapy with Temozolomide (TMZ) [1]. The use of TMZ, an oral alkylating agent, in association with RT can improve overall survival of patients with GBM [1-2]. TMZ is relatively safe and generally welltolerated. However, severe haematologic adverse events have been reported in several case reports and small series [3-11]. Recently, there has been growing interest in the analysis of gene polymorphisms that might be associated with an increased risk of hematologic toxicity [12-15].

We describe the case of a patient with GBM who developed severe and prolonged myelosuppression during concomitant daily TMZ and radiotherapy treatment. Analysis of polymorphisms in genes correlated with TMZinduced myelotoxicity was also performed.

\section{PRESENTATION OF THE CASE}

A 67-year-old man with a history of arterial hypertension was admitted to the emergency department with paresthesias of the left upper extremity.Magnetic resonance imaging of the brain showed an enhancing solid mass $(20 \mathrm{~mm})$ in the right parietal lobe and diffuse signal hyperintensity on T2-weighted images in the right hemisphere suggestive of gliomatosis cerebri (Fig. 1). The patient subsequently underwent a right temporal craniotomy and subtotal excision of the mass. The histopathological findings of the tumor were consistent with the diagnosis of GBM. Molecular analysis revealed methylation of the $0^{6}$-methylguanine-DNA-methyltransferase (MGMT) gene promoter in the tumor sample.

The patient was put on antiepileptic medication with levetiracetam and referred to us for adjuvant treatment. He began treatment with RT and concomitant daily TMZ at a dose of $140 \mathrm{mg} / \mathrm{die}$ $\left(75 \mathrm{mg} / \mathrm{m}^{2}\right)$. The planned RT dose was of 59.4 Gy to be given in 33 fractions of $1.8 \mathrm{~Gy}$. Prior to treatment the patient had a white blood cell (WBC) and platelet (PLT) count of $8.8 \times 10^{3} / \mathrm{uL}$ and $197 \times 10^{3} / \mathrm{uL}$, respectively. He did not receive co-Trimoxazole prophylaxis. During treatment, complete blood count (CBC) was carried out regularly once a week. He tolerated the combined therapy quite well, being mild fatigue the main side effect. After 21 of 33 planned fractions of radiation therapy and 30 of 47 days of TMZ, a platelet count of $11 \times 10^{3} / \mathrm{uL}$ was found. TMZ and RT were immediately stopped. One week later, when the platelet count dropped to $8 \times 10^{3} / \mathrm{uL}$ and multiple petechiae appeared on the trunk and arms, he was hospitalized in the medical oncology department. During hospitalization he became pancytopenic and required repeated platelet and red cell transfusions. He was treated with growth factors, 

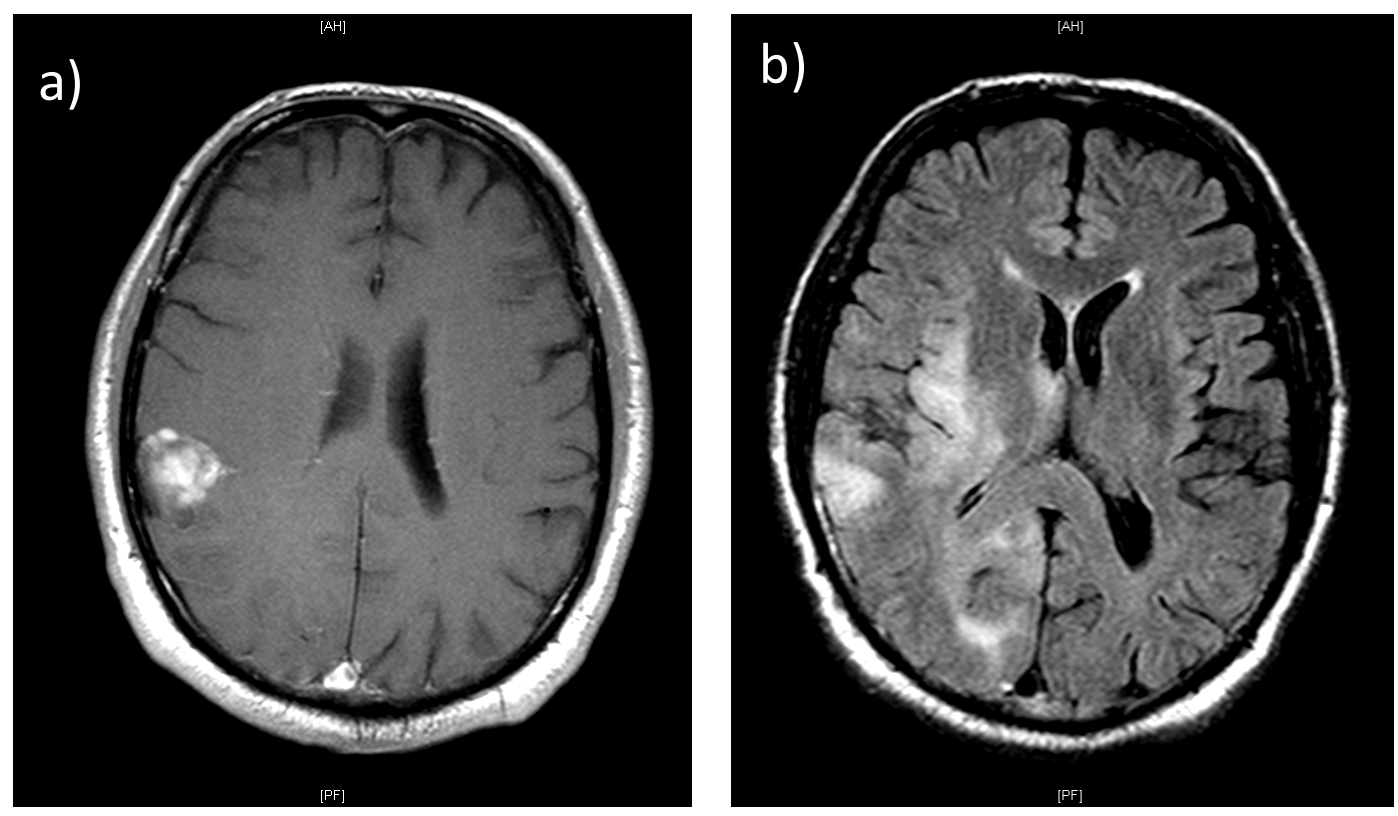

Fig. 1. Brain MRI of the patient at diagnosis

a) Enhanced lesion in the right parietal lobe on axial T1-weighted contrast image. b) Diffuse signal hyperintensity on axial T2-weighted image.

Table 1. Haematologic parameters over time

\begin{tabular}{llll}
\hline & Platelets & WBC & Hemoglobin \\
\cline { 2 - 4 } & $\mathbf{( \mathbf { x ~ 1 0 } ^ { 3 } / \mathbf { u L } )}$ & $\mathbf{( \mathbf { 1 ~ 1 \mathbf { 3 } ^ { 3 } } / \mathbf { u L } )}$ & $\mathbf{( \mathbf { g } / \mathbf { d l } \mathbf { ) }}$ \\
\hline Baseline values at the beginning of RT/TMZ & 197 & 8.8 & 13.5 \\
Day 13 of RT/TMZ & 140 & 7.8 & 14.4 \\
TMZ discontinuation (day 21 of RT/TMZ) & 11 & 2.28 & 11.3 \\
Day 6 from TMZ discontinuation & 12 & 0.16 & 9.4 \\
Day 9 from TMZ discontinuation & 29 & 0.09 & 9.2 \\
Day 15 from TMZ discontinuation & 16 & 0.26 & 8.0 \\
Day 22 from TMZ discontinuation & 7 & 1.61 & 7.8 \\
Day 29 from TMZ discontinuation & 11 & 2.14 & 7.9 \\
Day 41 from TMZ discontinuation & 23 & 2.20 & 7.0 \\
Day 65 from TMZ discontinuation & 34 & 4.3 & 9.8 \\
Day 125 from TMZ discontinuation & 16 & 2.99 & 7.6 \\
Day 163 from TMZ discontinuation & 16 & 2.77 & 8.4 \\
Day 206 from TMZ discontinuation & 16 & 3.29 & 9.1 \\
Day 305 from TMZ discontinuation & 34 & 4.03 & 9.8 \\
Day 402 from TMZ discontinuation & 72 & 4.35 & 13.5 \\
Day 590 from TMZ discontinuation & 130 & 3.60 & 9.3 \\
\hline
\end{tabular}
$R T$, radiotherapy; TMZ, temozolomide; $W B C$, white blood cell

erythropoietin and antibiotics. Serum Epstein Barr virus and cytomegalovirus IgMtiters were undetectable. Vitamin B12 and folic acid levels were normal. The values of white blood cells, platelets and hemoglobin $(\mathrm{Hb})$ during the whole period are shown in Table 1.

The patient was discharged from the hospital after one month with partial recovery of blood values. He completed his course of RT without concomitant TMZ. No adjuvant treatment with TMZ was started. Because of persistent pancytopenia a bone marrow aspirate and biopsy were performed one month after the end of treatment. The marrow was hypocellular (5-10\%) and the erytroid series was hyperplastic with marked signs of dysplasia. The granulopoietic and megakaryopoietic lineages were hypo- 
represented but without dysplasia. Several plasma cells with reactive features were observed in the marrow interstitium. Cytogenetic analysis showed a normal karyotype. Analysis of single nucleotide polymorphisms (SNPs) in the genes $\mathrm{NAD}(\mathrm{P}) \mathrm{H}$ dehydrogenase, quinone 1 (NQO1; rs1800566) and glutathione Stransferase pi 1 (GSTP1; rs1695) was carried out as previously described by Sylvester et al. [16]. Both SNPs were found to be wild-type (Table 2).

Table 2. Genotyping results

\begin{tabular}{|c|c|c|c|}
\hline SNPs & & $\begin{array}{l}\text { Increased } \\
\text { risk }\end{array}$ & $\begin{array}{l}\text { Global } \\
\text { frequencies [19] }\end{array}$ \\
\hline $\begin{array}{l}\text { GSTP1 } \\
\text { (rs1695) }\end{array}$ & $A G$ & AA & $\begin{array}{l}\text { AA: } 0.33, \text { AG: } \\
0.55, \text { GG: } 0.12\end{array}$ \\
\hline $\begin{array}{l}\text { NQO1 } \\
\text { (rs1800566) }\end{array}$ & AA & $\mathrm{GG}$ & $\begin{array}{l}\text { GG: } 0.60, \text { AG: } \\
0.37, A A: 0.03\end{array}$ \\
\hline
\end{tabular}

No further treatment was administered until 20 months from GBM diagnosis when, following disease progression, the patient underwent a second course of RT ( 37.5 Gy in 15 fractions of $2.5 \mathrm{~Gy}$ ) without TMZ. MRI of the brain performed one month after the end of RT showed further tumor progression and the patient died two years after the initial diagnosis of GBM. The values of the last CBC were: WBC: $3.6 \times 10^{3} / \mathrm{LL}$; PLT: 130 x $10^{3} / \mathrm{uL} ; \mathrm{Hb}: 9.3 \mathrm{~g} / \mathrm{dl}$.

\section{DISCUSSION}

TMZ is an oral alkylating agent with activity against brain tumors. TMZ is usually considered well tolerated and has a good toxicity profile. The cytotoxic effect of TMZ is caused by the generation of $\mathrm{O}^{6}$-methylguanine DNA adducts; when the enzymes of the mismatch repair system attempt to repair this alteration, the mechanism of apoptosis is activated. Myelosuppression is the most common haematologic adverse event of TMZ but it is a non-cumulative and reversible effect, and bone marrow recovery usually occurs within 28 days [17]. However, severe myelosuppression has been also reported. In the phase III trial of the European Organisation for Research and Treatment of Cancer (EORTC) and National Cancer Institute of Canada Clinical Trials Group ( $\mathrm{NCIC})$ of RT with concomitant and adjuvant TMZ in patients with newly diagnosed GBM, Stupp et al. [1] reported a $16 \%$ rate of grade $3-4$ myelosuppression. Grade 3-4 thrombocytopenia was observed in $3 \%$ and $11 \%$ of patients during concomitant and adjuvant treatment, respectively. Higher rates of myelotoxicity were reported by other authors. Doyle et al. [3] observed a $19 \%$ rate of severe myelosuppression in 16 patients with GBM treated with concomitant daily TMZ and RT. In a series of 52 patients with newly diagnosed highgrade gliomas receiving $\mathrm{RT}$ with concomitant and adjuvant TMZ, Gerber et al. [4] reported a $25 \%$ rate of grade 3-4 myelosuppression and $19 \%$ of grade 3-4 thrombocytopenia that caused discontinuation of treatment in $17 \%$ of patients. More recently, Villano et al. [18] reviewed all the TMZ-associated haematologic adverse events reported in the FDA Med-Watch database between 1997 and 2008, and they identified 228 cases of pancytopenia. Death occurred in 56 patients because of pancytopenia or its complications. The median duration of TMZ treatment was less than 3 weeks. Most of the cases were diagnosed within a week from the end of combined RT-TMZ treatment and, in 59 patients, during concomitant TMZ treatment, as in our case.

The association between genetic alterations in genes involved in DNA repair and drug metabolism and the risk of severe myelosuppression has been addressed in several studies [12-15]. Armstrong et al. [13] observed that the presence of the A allele of NQO1 and of the G allele of GSTP1 decreased the risk of toxicity. Reduced levels of NQO1 could lead to reduced activation of TMZ, while the relationship between GSTP1 and myelotoxicity is not explained. Moreover, the presence of the $G$ allele of MGMT in peripheral blood cells resulted in a significant increase in risk of toxicity, as a result of lower DNA repair and increased DNA damage. In our case, it was possible to perform only analysis of NQO1 and GSTP1 polymorphisms but not of MGMT. Both SNPs were found to be wild-type and no conclusions can be drawn from these findings. Data from a greater number of patients could help in treatment decision. However, currently genetic analysis is not routinely performed at our institution.

\section{CONCLUSION}

In conclusion, our case shows that severe and prolonged myelosuppression is a side effect that can occur relatively early during concomitant TMZ treatment and can negatively impact on patient's quality of life. Physicians should be 
aware of this potential long-term complication and should carefully evaluate hematopoietic function during TMZ treatment in order to eventually detect early bone marrow failure. Further studies are warranted to find out a correlation between genetic factors and the occurrence of severe hematologic toxicity.

\section{CONSENT}

Written consent for publication of case details was obtained from the patient's next of kin.

\section{ETHICAL APPROVAL}

Not applicable.

\section{COMPETING INTERESTS}

Authors have declared that no competing interests exist.

\section{REFERENCES}

1. Stupp R, Mason WP, van den Bent MJ, Weller M, Fisher B, Taphoorn MJ, et al. Radiotherapy plus concomitant and adjuvant temozolomide for glioblastoma. $\mathrm{N}$ Engl J Med. 2005;352(10):987-96.

2. Stupp R, Hegi ME, Mason WP, van den Bent MJ, Taphoorn MJ, Janzer RC, et al. Effects of radiotherapy with concomitant and adjuvant temozolomide versus radiotherapy alone on survival in glioblastoma in a randomised phase III study: 5-year analysis of the EORTC-NCIC trial. Lancet Oncol. 2009;10(5):459-66.

3. Doyle TJ, Mikkelsen T, Croteau D, Ali H, Anderson J, Beasse $\mathrm{R}$, et al. Fatal hematologic toxicity with prolonged continuous administration of temozolomide (TMZ) during radiation therapy (RT) in the treatment of newly-diagnosed glioblastoma multiforme (GBM): Report of a phase II trial. J Clin Oncol. 2005;23:1546.

4. Gerber DE, Grossman SA, Zeltzman M, Parisi MA, Kleinberg L. The impact of thrombocytopenia from temozolomide and radiation in newly diagnosed adults with high-grade gliomas. Neuro Oncol. 2007;9(1):47-52.

5. Morris EB, Kasow K, Reiss U, Ellison D, Broniscer A. Bone marrow transplantation for severe aplastic anemia secondary to temozolomide. J Neurooncol. 2009;91(2): 237-39.
6. Kopecký J, Priester P, Slovácek L, Petera J, Kopecký O, Macingova Z. Aplastic anemia as a cause of death in a patient with glioblastoma multiforme treated with temozolomide. Strahlenther Onkol. 2010;186(8):452-57.

7. Comez G, Sevinc A, Sever ON, Babacan T, Sarı I, Camci C. An unusual case of aplastic anemia caused by temozolomide. Case Report Med. 2010;2010:975039.

8. Villano JL, Collins CA, Manasanch EE, Ramaprasad C, van Besien K. Aplastic anemia in patient with glioblastoma multiforme treated with temozolomide. Lancet Oncol. 2006;7(5):436-38.

9. Noronha V, Berliner N, Ballen KK, Lacy J, Kracher J, Baehring J, et al. Treatmentrelated myelodysplasia/AML in a patient with a history of breast cancer and an oligodendroglioma treated with temozolomide: case study and review of the literature. Neuro Oncol. 2006;8(3):28083.

10. Kim SJ, Park TS, Lee ST, Song J, Suh B, Kim SH, et al. Therapy-related myelodysplastic syndrome/acute myeloid leukemia after treatment with temozolomide in a patient with glioblastoma multiforme. Ann Clin Lab Sci. 2009;39(4):392-98.

11. Hegi ME, Diserens AC, Gorlia T, Hamou MF, de Tribolet N, Weller M, et al. MGMT gene silencing and benefit from temozolomide in glioblastoma. $\mathrm{N}$ Engl $\mathrm{J}$ Med. 2005;352(10):997-1003.

12. Nagane M, Nozue K, Shimizu S, Waha A, Miyazaki $\mathrm{H}$, Kurita $\mathrm{H}$, et al. Prolonged and severe thrombocytopenia with pancytopenia induced by radiationcombined temozolomide therapy in a patient with newly diagnosed glioblastoma-analysis of O6-methylguanine-DNA methyl transferase status. J Neurooncol. 2009;92(2):227-32.

13. Armstrong TS, Cao Y, Scheurer ME, VeraBolaños E, Manning R, Okcu MF, et al. Risk analysis of severe myelotoxicity with temozolomide: the effects of clinical and genetic factors. Neuro Oncol. 2009;11(6):825-32.

14. Schaich M, Kestel L, Pfirrmann M, Robel $\mathrm{K}$, Illmer $\mathrm{T}$, Kramer $\mathrm{M}$, et al. A MDR1 (ABCB1) gene single nucleotide polymorphism predicts outcome of temozolomide treatment in glioblastoma patients. Ann Oncol. 2009;20(1):175-81. 
15. Lombardi G, Rumiato E, Bertorelle R, Saggioro D, Farina P, Della Puppa A, et al. Clinical and genetic factors associated with severe hematological toxicity in glioblastoma patients during radiation plus temozolomide treatment: a prospective study. Am J Clin Oncol. Epub; 2013.

16. Sylvester RK, Steen P, Tate JM, Mehta M, Petrich RJ, Berg A, et al. Temozolomideinduced severe myelosuppression: analysis of clinically associated polymorphisms in two patients. Anticancer Drugs. 2011;22(1):104-10.
17. Birner A. Pharmacology of oral chemotherapy agents. Clin J Oncol Nurs. 2003; 7(6 Suppl):11-9.

18. Villano JL, Letarte N, Yu JM, Abdur S, Bressler LR. Hematologic adverse events associated with temozolomide. Cancer Chemother Pharmacol. 2012;69(1):107113.

19. Collins FS, Brooks LD, Chakravarti A. A DNA polymorphism discovery resource for research on human genetic variation. Genome Res. 1998;8(12):1229-31. Erratum in: Genome Res. 1999;9(2):210.

(c) 2015 Scaringi et al.; This is an Open Access article distributed under the terms of the Creative Commons Attribution License (http://creativecommons.org/licenses/by/4.0), which permits unrestricted use, distribution, and reproduction in any medium, provided the original work is properly cited.

Peer-review history:

The peer review history for this paper can be accessed here: http://www.sciencedomain.org/review-history.php?iid=785\&id=38\&aid=6767 